\title{
Dispositivos frente a la hegemonía patriarcal, en procesos democrático-participativos
}

\section{Devices against patriarchal hegemony, processes democratic-participatory}

\author{
Tomás R. Villasante \\ Profesor Honorífico Universidad Complutense de Madrid \\ tvillasante@hotmail.com \\ Lola Hernández \\ loliherher@gmail.com
}

\begin{abstract}
Resumen: Desde los feminismos varios que hemos conocido se presentan nueve aportaciones básicas que vienen a reforzar aspectos metodológicos claves para las estrategias transformadoras y para las metodologías participativas. No se trata de partir de la supuesta «neutralidad científica», sino de la «parcialidad consciente», de las «visiones desde abajo», para construir «investigación científica y ético-política». Se plantean nueve saltos de enfoque (epistemológicos: ¿para qué?, ¿para quién?); también aportamos nueve acciones y herramientas, y concluimos que nueve productos son posibles en los procesos para superar las situaciones de marginalidad y opresión. Entendemos que los procesos de autoorganización social en las estrategias y movimientos del siglo XXI vienen a corroborar muchos de estos postulados que aquí se recogen. Aún quedan restos del patriarcado y del elitismo vanguardista en las formas en que se articulan muchos partidos y movimientos, pero aquí se aportan argumentos y herramientas para poder superar los vicios heredados.
\end{abstract}

Palabras clave: Patriarcado, metodologías participativas, sociopraxis, transducciones, grupos motores, autoorganización.

\footnotetext{
Abstract: From the various feminisms we have known nine basic contributions which reinforce key methodological issues for transformative strategies and participatory methodologies. It is not from the supposed «scientific neutrality» but of «political-ethical and scientific research,» «conscious bias», «visions from below» to build. Also we contribute nine shares and tools, and concluded that nine
} 
products are possible in the processes to overcome situations of marginalization and oppression: nine jumps approach (what for whom epistemological?) arise. The processes of self-organization strategies and social movements of the XXI century we understand that corroborate many of these postulates are collected here.

Keywords: Patriarchy, participatory methodologies, sociopraxis, transductions, powerplants, self-organization. 
«1. Debe reemplazarse el postulado de la investigación desprovista de valores, de la neutralidad y la indiferencia hacia los objetos de estudio, por la parcialidad consciente, alcanzada a través de la identificación parcial con los objetos de estudio.

2. Debe sustituirse la relación vertical entre el investigador o investigadora y los objetos de estudio, la visión desde arriba por una visión desde abajo para aplicar una investigación científica y ético-política.

3. Debe sustituirse el conocimiento espectador contemplativo y no participativo por una participación activa en las acciones, movimientos y luchas en favor de las condiciones de vida entre mujeres y hombres.

4. La participación en las acciones y luchas sociales y la integración de la investigación en estos procesos implica asimismo que la modificación del status quo se convierta en el punto de partida de una indagación científica. El lema de este enfoque podría ser: si quieres algo, deberás cambiarlo.

5. El proceso de investigación debe convertirse en un proceso de concientización, tanto para las llamadas sujetos de estudios como para los sujetos estudiados, es decir, la investigación debe inspirarse en el estudio de las condiciones de la opresión para aportar las herramientas suficientes a los sujetos estudiados en la mejora de su calidad de vida.

6. En definitiva, debe ir acompañada del estudio de su historia individual y social para analizar con rigurosidad su situación de marginalidad y opresión.»

(Mies y Shiva, 1993: 59-83)

Hay mucho miedo en el mundo y mucho conformismo con algunas tradiciones que nos suelen paralizar. Aún en condiciones de opresión y explotación muy claras, no nos atrevemos a protestar, ni a seguir a líderes que nos muestran alternativas, porque se piensa que no sirve de nada. Se suele dar como natural que no vale la pena meterse en líos, que no hay nada que hacer, incluso sabiendo que vamos a una catástrofe ecológica o social, porque los superpoderes internacionales no permiten cambios, o que los líderes acaban distanciándose de la gente (aunque aún sean necesarios), o bien que se pelean entre ellos por protagonismos antes que solucionar los problemas reales. Pero la actual crítica del patriarcado muestra que las cosas pueden cambiar y que se puede superar algún determinismo social. Las familias y sus relaciones de poder cambiaron mucho a través de la historia y entre las diferentes culturas, e incluso ahora hay formas de nuevas familias que no responden al patriarcado. No es un proceso a corto plazo, pero hay valiosas cuestiones para reflexionar y hacer en consecuencia. Esto sirve para actuar en los procesos transformadores con nuevos criterios de autoorganización que no repitan los errores pasados de muchos movimientos y partidos que eran o aún son reflejo de las organizaciones patriarcales de la sociedad. 
Las aportaciones de las muy variadas corrientes feministas y antipatriarcales (críticas desde las nuevas masculinidades y desde los adolescentes o los mayores) nos estimulan en varias direcciones. Presentamos tres columnas de ondas, que van desde lo más personal (que se relaciona con lo que vivimos en los pequeños grupos) hasta lo más general de la sociedad (el mundo en que vivimos y nos condiciona), pasando por las ondas intermedias (que relacionan la vida cotidiana de nuestros grupos familiares, de trabajo, etc., con aquellas comunidades locales y profesionales en que nos insertamos, y con la sociedad en general). En todos esos ámbitos encontramos aportaciones desde las luchas antipatriarcales, que además nos aportan a las construcciones de estrategias eficientes en las metodologías participativas para las transformaciones sociales. Como dicen nuestras autoras de referencia, «si quieres algo, deberás cambiarlo». La «sociopraxis» es una serie de metodologías al servicio de los movimientos populares para conseguir cambios significativos, al ritmo en que la gente del común quiera caminar o saltar hacia ellos, por eso nos parece profundamente democrática.

Partimos de recoger algunos aspectos en el sentido de «enfoques básicos». Es decir, preguntas de tipo epistemológico sobre el sentido de nuestra posición ante los procesos sociales. ¿Para qué hacemos esto? ¿Para quién (y con quién) estamos actuando? Hay sujetos implícito/as o explícito/as con intereses en juego, que no son marginales, sino fundamentales en todo lo que hacemos (tanto si es para una empresa, una Administración, una universidad o un movimiento social). Y hay un «para qué» de fondo, una intencionalidad de cualquier proceso humano que muchas veces no se presenta de modo explícito, pero que es muy importante calibrar para qué nos sirve a nosotros y para qué le sirve a la sociedad lo que hacemos (en la onda corta, en la media y en la larga). No es inocente nada de lo que hacemos, y por eso nos cuestionamos las «éticas sociopolíticas» tanto de nosotras mismas como personas como de los procesos a los que contribuimos. Presentamos primero el conjunto y luego vamos viendo cómo lo podemos explicar a partir de las autoras que nos ilustran y de nuestras propias prácticas. 
Distinciones y articulaciones entre feminismos y sociopraxis

\begin{tabular}{|c|c|c|c|}
\hline $\begin{array}{c}\text { Ondas } \\
\text { Aspectos }\end{array}$ & $\begin{array}{c}\text { Onda corta: grupos } \\
\text { ÉTICAS } \\
\text { SOCIOPOLÍTICAS } \\
\text { «TRANSDUCTIVAS» }\end{array}$ & $\begin{array}{l}\text { Onda media: comunidades } \\
\text { SALTOS MICRO-MACRO } \\
\text { "AUTOORGANIZADOS» }\end{array}$ & $\begin{array}{c}\text { Onda larga: sociedades } \\
\text { PROCESOS } \\
\text { SOCIALES CON } \\
\text { «IDEAS-FUERZA» }\end{array}$ \\
\hline $\begin{array}{l}\text { ENFOQUES } \\
\text { (¿Para quién? } \\
\text { ¿Para qué?) }\end{array}$ & $\begin{array}{l}\text { Frente a «determinismos } \\
\text { lineales causa-efecto», } \\
\text { más allá de «leyes y éticas } \\
\text { ejemplares», «LA } \\
\text { MUJER NO NACE, SE } \\
\text { HACE»: } \\
\text { CON } \\
\text { AUTORREFLEXIÓN, } \\
\text { desde los Sistemas } \\
\text { Emergentes } \\
\text { (S. de Beauvoir, D. } \\
\text { Haraway, } \\
\text { R. Braidotti, S. Federicci, } \\
\text { F. Guattari, etc.) } \\
\text { Autorreflexión grupal } \\
\text { con Sociodramas, } \\
\text { derivas, etc. }\end{array}$ & $\begin{array}{l}\text { Frente a «estructuras del } \\
\text { poder patriarcal» } \\
\text { individualizador, } \\
\text { «LO PERSONAL ES } \\
\text { POLÍTICO», } \\
\text { ESTRATEGIAS desde los } \\
\text { ENTRAMADOS } \\
\text { COTIDIANOS, } \\
\text { desde el «análisis de redes» } \\
\text { y las estrategias } \\
\text { comunitarias (E. Bott, } \\
\text { L. Dominelli, E. MacLeod, } \\
\text { R. Gutiérrez Aguilar, } \\
\text { P. Freire, etc.) } \\
\text { Mapeos estratégicos y } \\
\text { «conjuntos de acción» }\end{array}$ & $\begin{array}{l}\text { Frente a la «neutralidad } \\
\text { de la ciencia», más allá de } \\
\text { las «distancias sujeto- } \\
\text { objeto», } \\
\text { EMOCIONES Y } \\
\text { CIENCIAS } \\
\text { desde la PRAXIS } \\
\text { (implicación } \\
\text { en acción-reflexión- } \\
\text { acción), } \\
\text { (V. Shiva, M. Mies, E. } \\
\text { Fox Keller, K. Knorr- } \\
\text { Cetina, G. Verden } \\
\text { Zöller-H. Maturana, etc.) } \\
\text { Negociación para } \\
\text { estrategias } \\
\text { transformadoras e } \\
\text { integrales }\end{array}$ \\
\hline $\begin{array}{l}\text { (herramientas) } \\
\text { ACCIONES }\end{array}$ & $\begin{array}{l}\text { Frente a la } \\
\text { «simplificación de la } \\
\text { dialéctica», y más allá de } \\
\text { la «concienciación } \\
\text { mediática», } \\
\text { «ESCUCHA ACTIVA» } \\
\text { de los «HACERES»y } \\
\text { «DECIRES» } \\
\text { desde la «comunicación } \\
\text { popular»y la } \\
\text { autoformación-acción. } \\
\text { (S. Rivera, M. Montero, } \\
\text { R. Reguillo, R. Braidotti, } \\
\text { J. Galtung, etc.) } \\
\text { Superar los dilemas y } \\
\text { las paradojas con } \\
\text { multilemas }\end{array}$ & $\begin{array}{l}\text { Frente a «estilos } \\
\text { patriarcales y de } \\
\text { ancestros autoritarios», } \\
\text { «SUJETOS EN } \\
\text { PROCESOS» } \\
\text { GENERACIONALES } \\
\text { desde el E.C.R.O. y el } \\
\text { esquizoanálisis al } \\
\text { R.O.C.E. } \\
\text { (J. Kristeva, A. } \\
\text { Hernando, } \\
\text { S. Rolnik, A. P. } \\
\text { Quiroga, } \\
\text { E. Pichón-Rivière, etc.) } \\
\text { Procesos con espacios } \\
\text { de creatividad social } \\
\text { (talleres para } \\
\text { devoluciones) }\end{array}$ & $\begin{array}{l}\text { Frente a las } \\
\text { «explotaciones y la } \\
\text { neocolonización elitista», } \\
\text { MOVILIZACIONES con } \\
\text { «GRUPOS MOTORES } \\
\text { CUIDADORES» } \\
\text { desde los movimientos } \\
\text { sociales emergentes e } \\
\text { inclusivos. } \\
\text { (R. Luxemburg, A. } \\
\text { Davis, G. Spivak, C. } \\
\text { Carrasco,R. Gutiérrez } \\
\text { Aguilar, etc.) } \\
\text { Grupos motores, y } \\
\text { reparto de poderes, con } \\
\text { grupos de tarea }\end{array}$ \\
\hline
\end{tabular}




\begin{tabular}{|c|c|c|c|}
\hline $\begin{array}{c}\text { Ondas } \\
\text { Aspectos }\end{array}$ & $\begin{array}{c}\text { Onda corta: grupos } \\
\text { ÉTICAS } \\
\text { SOCIOPOLÍTICAS } \\
\text { «TRANSDUCTIVAS» }\end{array}$ & $\begin{array}{l}\text { Onda media: comunidades } \\
\text { SALTOS MICRO-MACRO } \\
\text { «AUTOORGANIZADOS» }\end{array}$ & $\begin{array}{l}\text { Onda larga: sociedades } \\
\text { PROCESOS } \\
\text { SOCIALES CON } \\
\text { «IDEAS-FUERZA» }\end{array}$ \\
\hline $\begin{array}{l}\text { (productos) } \\
\text { ESTRATEGIAS }\end{array}$ & $\begin{array}{l}\text { Frente a las } \\
\text { «postverdades» de los } \\
\text { medios dominantes, } \\
\text { «ASTUCIAS»Y } \\
\text { «DESBORDES» } \\
\text { REVERSIONES } \\
\text { POPULARES, } \\
\text { desde la autoorganización } \\
\text { de base y el «buen } \\
\text { convivir», } \\
\text { (D. Juliano, M. J. } \\
\text { Izquierdo, J. Sabadell, C. } \\
\text { Vega, F. Cembranos, } \\
\text { comunidades en } \\
\text { transición, cooperativas } \\
\text { Iitegrales, etc.) } \\
\text { Grupos inteligentes. } \\
\text { Disfrute y ejemplos del } \\
\text { buen convivir }\end{array}$ & $\begin{array}{l}\text { Frente a lo «representativo» } \\
\text { de «baja intensidad»y } \\
\text { «sectarismos», } \\
\text { «AUTOORGANIZACIÓN» } \\
\text { desde INICIATIVAS DE } \\
\text { BASE de los movimientos } \\
\text { por las democracias } \\
\text { participativas } \\
\text { (H. Henderson, E. Olstron, } \\
\text { H. Wainwrigth, M. } \\
\text { Harnecker, M. E. R. Palop, } \\
\text { Mov. Chipko, Pro- } \\
\text { Comunes, Kerala, etc.) }\end{array}$ & $\begin{array}{l}\text { Frente a la } \\
\text { «financiarización», } \\
\text { «dictadura de los } \\
\text { mercados»y la } \\
\text { «especulación global» } \\
\text { «LA VIDA EN EL } \\
\text { CENTRO»: } \\
\text { SUSTENTABILIDADES } \\
\text { y ECONOMÍAS } \\
\text { SOLIDARIAS } \\
\text { desde la economía } \\
\text { feminista, ecofeminismos, } \\
\text { y la agroecología. } \\
\text { (V. Shiva, A. Pérez } \\
\text { Orozco, Lia Tiriba, Y. } \\
\text { Herrero, Ch. Laval y P. } \\
\text { Dardot, etc.) } \\
\text { Planes de acción } \\
\text { integrales y sostenibles }\end{array}$ \\
\hline
\end{tabular}

Podemos explicar estos nueve «saltos-dispositivos antipatriarcales» que nos parece que suelen diferenciar un proceso (hecho con «sociopraxis» y garantías metodológicas) de otros hechos con más voluntad y buena intención que conocimientos de los problemas que suelen surgir. Pasamos a proponer unas aclaraciones y distinciones sobre los sentidos que damos a estos «saltos» para que no se puedan confundir solo con fases o etapas de un proceso. Proponemos unas aclaraciones y distinciones, porque en cada etapa/salto hay novedades de enfoques, de acciones y de productos a conseguir, muchas de las cuales vienen de una crítica a las formas patriarcales en que nos han formado:

a) Estamos tratando de hacer estrategias transformadoras. Y dentro de un proceso hay fases y etapas secuenciales que pueden alterar su orden, pero que deben recorrerse en algún momento para construir sistemas más avanzados de conciencia de autoorganización y resultados operativos. Los saltos en este sentido no solo son cumplimentar las fases, en el orden que sea, sino construir algunos resultados tanto internos para el «grupo motor» como externos para la comunidad en cuestión (sea esta local, laboral, sectorial, festiva, etc.). 
b) Son también saltos de enfoques en los procesos metodológicos, porque no basta con dinamizar o facilitar solo con buenas intenciones, con voluntarismo basista, sino que parece preciso establecer distinciones sobre lo que supone cada «acción», cada «dispositivo» empleado, para qué sirve y para qué no sirve. Los saltos que se proponen no son cualquier dispositivo técnico, sino aquellos que nos parecen que marcan unas distancias con las formas no críticas de enfocar procesos participativos. Establecemos distancias con muchos estilos patriarcales que son habituales, incluso aún cuando hablen de participación. Estos enfoques en cada apartado los vamos a relacionar presentando otras formas más convivenciales y cuidadosas de hacer los procesos, más antipatriarcales.

c) Además, son «dispositivos»o «herramientas», «acciones» y «productos», pues nos parece ambas cosas a la vez cada acción con sus productos correspondientes. Por ejemplo, tomemos la autorreflexión como un enfoque (de base epistemológica no determinista y autocrítica): es una acción (mediante un sociodrama sobre los liderazgos de la vida cotidiana, o una deriva-paseo por lugares que nos señalan mujeres locales) y es un producto (acuerdos sobre los dolores iniciales en un proceso y la posible conformación de un grupo motor). Solo en la medida en que se dan estas circunstancias podemos considerar que se da un salto metodológico (respecto a otras metodologías más convencionales, que no se plantean esto, y respecto a procesos que hacen técnicas sin justificar por qué o para qué las acciones y los productos).

Vamos a enunciar cada «salto», y al final de cada uno (para concretar aún más) vamos a poner de manera telegráfica lo que supone en su enfoque diferencial con otras metodologías, qué tipo de acciones puede precisar y a qué productos se pretende llegar.

\section{1. «LA MUJER NO NACE, SE HACE» (AL HOMBRE TAMBIÉN LO HACEN)}

Se trata de autorreflexionar sobre los prejuicios básicos que nos constituyen antes de salir a ver las cosas que nos ocurren fuera como «naturales». Desde los feminismos se ha ido dejando claro que ser mujer es una construcción social, más allá del sexo con que se nace. Pero también desde las nuevas masculinidades se plantean los problemas que causa el machismo en los varones, que se han de «diferenciar» como norma de «ser mujer», con lo que se pierden muchas oportunidades de la vida y se encierran en estereotipos bastante ridículos. Se supone que un hombre no debe llorar o mostrarse en calzoncillos abrazándose con otros hombres, y menos en público. Pero al mismo tiempo en un campo de futbol 
lo que aplaude la gente son esos abrazos y lloros de alegría cuando se mete un gol. Contradicciones de cómo se nace y cómo nos educan según unos ritos u otros. Por eso conviene que veamos las actitudes ridículas que tenemos antes de salir a mirar a los demás, y sobre todo no juzgar otras conductas, que muchas veces solo son convenciones de una subcultura, y que mejor será pensar si son nuestras gafas las que pueden estar fallando.

Las derivas, las líneas del tiempo, y otras técnicas que usamos, tienen sus raíces en los «cuidados colectivos» convivenciales, que se suelen producir en algunas comunidades, donde las partes no patriarcales suelen ser las encargadas de poner al día juegos reflexivos, de tipo crítico y autocrítico de los colectivos. Por eso nos interesa cómo nos ve un ama de casa, o cómo se comunican las personas paseando, o reclamar los prejuicios que se observan en los cuerpos (en un juego de rol o un sociodrama) que comentan otras personas. Sacar a flote los prejuicios y las oportunidades desde un principio, los juegos que se abren con distintas variables, no dar por supuesto que lo que parece, se ve o se dice en un primer momento pueda ser «el problema»o «la verdad». Al principio estamos solo en el grito o el síntoma, y el problema (de fondo) es algo a construir; necesitamos un proceso transductivo para llegar a ello.

Cuando se inicia un proceso, o alguien se suma a él de nuevo, es conveniente no precipitarse y hacernos las preguntas de fondo sobre el mismo. ¿Para qué? y ¿para quién? tiene sentido lo que está sucediendo o lo que queremos que suceda. Y no solo por lo que dice la gente, sino también, y sobre todo, por lo que está pasando, por los hechos mismos en que nos encontramos. Nos implicamos con los «estilos transductivos» que van más allá de lo que se define como sexo, clase o ideología, y que parten de lo que se hace, en lo situacional de cada momento, en las provocaciones que se reciben o se plantean en cada caso. Transducir es pasar de una energía a otra, de unas acciones a otras, sentir y hacer desde otros supuestos más complejos (ej.: la clase no es determinista, sino sobre todo construida; el sexo es solo una circunstancia y no todo lo que nos define; la edad, igual, etc.).

Enfoque: ¿Quién observa al observador/a? ¿Ponemos en cuestión nuestro punto de arranque? Acción: Desde fuera del equipo, o con dispositivos de autorreflexión, poder cruzar inteligencias diversas. Producto: Cierta conciencia y autolimitación de algunos prejuicios para sesgar menos el proceso en que nos metemos.

\section{2. «LO PERSONAL ES POLÍTICO». LAS ESTRATEGIAS DE VIDA EN COMÚN}

Partimos de que la comunicación de lo cotidiano produce información básica y valores de todo tipo. Tomar en cuenta las redes y los tejidos sociales, y no tanto las jerar- 
quías (organigramas mucho más patriarcales), tiene que ver con unas ciencias sociales que relativizan los poderes dominantes y que redescubren las relaciones cotidianas como base de toda la sociedad. Los feminismos partieron desde estos supuestos. El papel de las personas de base en los entramados de la comunicación de la vida cotidiana es fundamental, pues comentan, o no, y de qué manera, lo que circula por la TV y por las redes sociales, configuran la opinión pública «desde abajo», en los sectores de «seguidores» (1 o $2 \%$ ) y «retransmisores» (entre un 25 y un $30 \%$ de la sociedad). Las estrategias de vida tienen que ver con la clase social, el género, la generación, las culturas, etc., de forma que en cada caso solo se puede saber si construimos una radiografía específica para cada caso (las relaciones personales que no se ven pero mueven a la sociedad). Si prestamos atención a estos procesos personales en red, son más fáciles de cambiar las relaciones en una comunidad que las condiciones externas o los liderazgos patriarcales.

Por eso se trata de hacer «mapas estratégicos» construidos en cada situación con las personas que conocen la vida cotidiana. No son mapas geográficos, sino de grupos y personas a las que afectan al menos cuatro variables (clase social, poder de comunicación y tipo de organización, afinidad o ajenidad al proceso, y relaciones de confianzas o rechazo, miedos, etc.). Aun cuando las condiciones de clase o las ideologías sean semejantes, los procesos suelen tomar caminos muy distintos según las «relaciones personales». Aunque no se nombren las peleas dentro de una comunidad, éstas existen y se han de tener en cuenta para las estrategias de cambio (¿qué une y qué separa?). Con los «mapas estratégicos de actores» podemos visualizar los «conjuntos de acción» y sus posibilidades, más que con los liderazgos patriarcales (lo que se ve de los dirigentes). Estos liderazgos existen (y son difíciles de cambiar), pero también existen otras relaciones de colaboración (fiestas, problemas evidentes, etc.) en las que pueden fomentarse acciones unitarias y desbordar las situaciones estancadas.

En estas radiografías de relaciones se puede ver en qué confluyen los sectores afines y los diferentes dentro de una causa concreta frente a los opuestos, y en consecuencia se pueden trazar estrategias que aíslen y dividan a los inmovilistas para conseguir los objetivos comunes con la fuerza de la mayoría para ese asunto en concreto (aun cuando en otros asuntos no se pueda actuar unidos). Por eso, partir de las relaciones personales (junto a otras variables) es un punto muy importante a manejar, pues los cambios y las confluencias entre sectores de base generan fuerzas y experiencias que son claves en cualquier proceso social.

Enfoque: Reconocer la complejidad de relaciones en los entramados sociales (clase, género, afinidad cultural, organización y comunicación, miedos y confianzas). Acción: mapeo estratégico, como radiografía de las relaciones que no se ven en superficie, pero 
deciden en el fondo. Producto: Muestra relacional para partir de los nudos de información de base, y «conjuntos de acción» para alianzas viables en el proceso.

\section{LAS EMOCIONES EN TODAS LAS CIENCIAS SENTIPENSANTES}

En la cita que encabeza este texto ya las autoras nos advierten de que las ciencias tienen que ser construidas desde abajo, desde los intereses y sentires de la gente. Dicho de otro modo: «pasión no quita conocimiento», sobre todo si la pasión es por ser eficientes en la transformación social. Nunca hay neutralidad en las ciencias, pues siempre las construimos en un entramado de poderes más o menos visibles, y lo más peligroso es desconocer que existen tales influencias. Los que a veces se consideran «objetos de la ciencia» tienen sus propias estrategias, y se rebelan ante o engañan a los que se creen más científicos, sobre todo cuando se trata de humanos que presienten algún peligro al ser muy estudiados. Las científicas feministas, y no solo ellas, han construido una crítica muy fundamentada sobre los errores de las «ciencias objetivas». Los sistemas emergentes de las ciencias actuales parten más de las ciencias comprometidas no solo en sus consecuencias, sino desde lo que son sus supuestos básicos (tanto en las ciencias naturales como en las sociales).

La praxis entendida como acción-reflexión-acción viene a coincidir con el postulado ya dicho de «si quieres algo, deberás cambiarlo». O sea, es cosa de ponerse a cambiar algo y reflexionar sobre cómo se puede llegar a un cambio a mejor. Insistir en la transducción como verificación científica más que en tratar de elucubraciones solo lógicas. Lo «sentipensante» está en la base de los movimientos sociales y de la investigación-acción participativa, pero también en las investigaciones feministas más creativas y fundamentadas. «Concientización» no tanto como señalar los problemas desde quien cree conocerlos, sino cómo construir conjuntamente en espacios colaborativos todas las complejidades y emergencias posibles. Por eso los sujetos que estudian deben también aprender en el proceso tanto como los demás sujetos, autoconcienciarse (si no ocurre, algo va mal).

Para comenzar hay que negociar, y no dar por sentadas las palabras de quien manda, es una habilidad para hacer grupo y para hacer buenas relaciones entre grupos o colectivos. Hacer estas tareas con cuidados, y no con las imposiciones habituales, también es algo que se puede aprender con los enfoques no patriarcales de negociar y formar grupos. Hay distintos intereses (públicos u ocultos) y diversas inteligencias en estos juegos de posiciones iniciales. Aclarar desde un principio cuál va a ser el perfil y el compromiso técnico-profesional es importante por lo que venimos diciendo, pero también los 
compromisos de quienes tengan el poder de ejecutar, y hasta dónde se puede llegar para no engañarnos ni engañar a la gente. Quienes participan desde la base, la inteligencia de lo común, es importante que puedan hacerlo según aquellos dispositivos que más les interesen (grupos motores, comisiones de seguimiento, equipos multimedia, etc.). La negociación inicial y el plan de trabajo es algo necesario para poder obtener resultados (objetivos, tiempos a dedicar, metodologías y algunas técnicas, etc.).

Enfoque: Construcción colectiva desde las diversas instancias iniciales y las diversas inteligencias que parecen necesarias. Acción: Constitución de acuerdos con comisiones de seguimiento, de grupos motores, etc. Producto: Concretar la metodología para cada caso concreto, y un plan de dinamización según las posibilidades.

\section{ESCUCHA ACTIVA, MÁS ALLÁ DE LOS DILEMAS DOMINANTES}

Escuchar a todas las partes, más que adoctrinar, y abrir los dilemas que suele formular el poder, son formas antipatriarcales de establecer las relaciones humanas. Reconocer la diversidad de posturas, y no solo la del dirigente, abrirse a posiciones semiocultas con nuevos campos, no es como lo suele hacer el saber patriarcal, sino todo lo contrario. Planteamos compartir los «haceres» de la gente, desde los haceres relacionales, y escuchar los «decires» en donde la gente está, más que llamar a reuniones como convoca el modelo patriarcal. Pasear y conversar con actividades, los dolores y los placeres desde la vida cotidiana, sintonizar con la historia local y con las historietas de cada cultura, entendiendo las contradicciones en los sectores populares (que no son pocas).

Hay un decir oficial y público que suele ser acaparado por algún dirigente o por algún medio de comunicación, aunque también suele encontrar su oponente. Es decir, que tratan de representarnos con un dilema las dos «únicas» posiciones que les interesan y que formulan como excluyentes la mayor parte de las veces. Pero sabemos que hay otras posiciones ocultas entre la gente, no solo el «café para todos» del padre de familia, sino que la madre sabe qué le pasa a cada hijo/a y qué puede ser más conveniente en cada caso. Estas posiciones ocultas, y sobre todo los haceres reales (que no coinciden solo con las dos posiciones dominantes) abren un abanico interesante de posibilidades. En unos casos niegan ambas, en otras toman algo de unas y otras, e incluso puede que se encuentre que es posible sumar las ventajas de unas y otras. Es lo que algunos científicos llaman «tetralemas», «pentalemas», o en nuestro caso «multilemas». Estos juegos de contradicciones y paradojas que nos ocurren a diario pueden ser muy productivos, y de hecho lo son en diversas disciplinas (lingüística, resolución de conflictos, etc.). Por eso nos pareció muy interesante usar estas deconstrucciones de las posiciones discursivas y 
prácticas para poder devolver a la gente sus propias palabras y actos y que puedan construir sus estrategias sin claudicar en los dilemas patriarcales.

Enfoque: Superar algunos dilemas superficiales que nos encuadran y abrirnos a las posiciones y acciones ocultas. Acción: Recogida de las posturas diferenciadas con multilemas para hacer creativas las contradicciones de la gente. Producto: Deliberación de posiciones discursivas/activas por los protagonistas y profundización en sus causas y en posibles vías superadoras.

\section{COPRODUCIR EN PROCESOS DE CREATIVIDAD SOCIAL}

Somos sujetos paridos y por tanto partidos, somos sujetos en procesos, inacabados y vulnerables.

Los cambios profundos se instalan desde estrategias generacionales, tal como los movimientos feministas nos enseñan desde el siglo XIX. En cada oleada se han centrado en un derecho a conseguir, más allá de sus divisiones internas (sufragistas, despenalizar el aborto, igual salario por igual trabajo, contra las violencias machistas, etc.). No tanto el cambio por arriba del Estado o de la economía, sino el hacer común por abajo, en una o varias generaciones, los cambios que ya no se vuelven atrás, porque también se intenta involucrar a los varones y a los poderes con una nueva cultura que hace imprescindibles esos derechos.

El patriarcado no solo pesa sobre las mujeres, sino sobre las distintas edades diferentes a la del «pater familia». Un ejemplo de cambio generacional lo vivimos en los años 90 con miles de jóvenes que acamparon en cincuenta ciudades por el $0,7 \%$ del Gobierno español para los países empobrecidos. A partir de los dolores-placeres de estos adolescentes aprendimos bastante, simplemente poniendo nuestra tienda junto a las suyas y escuchando en sus asambleas. Posiblemente no era más que un grito generacional adolescente (en el encuadre de una caridad bien entendida). Pero lo interesante es que desbordaron a sus líderes en sus asambleas, y abrieron un camino generacional que podríamos seguir en diversas movilizaciones hasta el 15M y las «mareas» (de la educación, la sanidad, etc.) años más tarde. En sus asambleas no les interesaba tanto la huelga de hambre de unos dirigentes como la movilización hacia los sectores de base de la ciudad, y posteriormente pasaron del $0,7 \%$ a la anulación de la deuda externa. Se aprende colectivamente en la acción conjunta.

Por eso no se trata de imponer una línea para la devolución, como si ya se supieran las conclusiones, sino respetar y seguir los pasos que cada comunidad o colectivo quiera dar, que no es la forma patriarcal a que nos tienen acostumbrados, sino formas de 
cuidados con los conjuntos de acción en presencia. Lo hacemos con reuniones y con talleres donde las dinámicas fomentan la creatividad de los presentes, pero siguiendo su ritmo generacional. No se trata tanto de denunciar lo dominante patriarcal en su conjunto, sino de encontrar lo emergente, lo que desbloquea los cuellos de botella, aquellas posiciones (incluso minoritarias inicialmente) que se van abriendo paso en cada caso, posiciones superadoras más allá de quien las ha propuesto, construcciones colectivas que hacemos en estos «talleres de devolución creativa», poder construir en «espacios transversales» de género, edad, clase, etc. Pasamos de los «grupos operativos» del E.C.R.O. (esquemas conceptuales referenciales y operativos) que nos constituyen a todas las personas para provocar los R.O.C.E. (relaciones operativas para conceptos eficientes). Es decir, reuniones y actividades donde las relaciones emotivas facilitan que avancemos en colectivo a posiciones superadoras por nuestras propias experiencias.

Enfoque: Reflexividad (de «segundo grado») con la gente implicada, que se replantea los primeros síntomas para pasar a problemáticas mucho más profundas e integrales y a priorizar caminos que ven viables. Acción: Talleres o asambleas con grupos de trabajo, donde se toman decisiones sobre las informaciones plurales que se han recogido de las contradicciones que hay en la sociedad. Producto: Un autodiagnóstico, con prioridades y alianzas para poder pasar a la fase de actuaciones.

\section{CUIDAR LOS PROCESOS Y LAS MOVILIZACIONES}

Sabemos que en algún grado estamos en sistemas de opresión y explotación, pero las urgencias de algunos dirigentes a veces matan los procesos. Para que un proceso o una movilización se pueda consolidar desde abajo ha de tener muy en cuenta «los cuidados» con los grupos que participan, ha de articular algunos sueños de futuro con lo pragmático de lo inmediato, lo que no suele ser el estilo de lo patriarcal, en el que algunos «dirigentes» o los «expertos» dicen lo que hay que hacer. Lo que se ve y resaltan los medios son las figuras que encabezan, porque es más simple para explicar y reducir a las imágenes complejas de lo que realmente se está cuajando. Pero en las huelgas de mujeres, como en el $15 \mathrm{M}$ o en otras movilizaciones masivas, no es preciso saber quién es el dirigente, sino qué multitud de grupos anónimos es el que impulsa y cuida estos procesos. Y ahí es donde suele estar la clave de sus éxitos, cosa que las visiones superficiales suelen desconocer. En 2015 las candidaturas municipalistas del cambio tuvieron éxito sobre todo por la actividad de numerosos grupos en la base y el entusiasmo que contagiaron más que por el tirón de unos líderes (solo parcialmente conocidos). Pero cuando los dirigentes entraron en rivalidades para las listas de 2019, el entusiasmo decayó y los grupos motores de la base no se movilizaron de igual forma. 
Los feminismos han reivindicado los cuidados en las prácticas cotidianas desde la labor que las mujeres han tenido que hacer en la división patriarcal del trabajo. Hay mucho que aprender, no solo en las tareas domésticas, sino en la forma de relacionarnos de manera no competitiva con las personas del entorno. Aportamos la práctica y las formas de «grupos motores cuidadores» que venimos promoviendo en las metodologías y democracias participativas en que nos hemos ido formando. No son directivos o representantes tradicionales, sino algunas personas del común (bastantes mujeres) que aspiran a colaborar en cosas concretas, en la medida de sus capacidades. Si cada cual hace lo que siente que está capacitado y le apetece hacer, es más fácil que la tarea salga adelante. La cuestión pasa entonces a cómo articular y cuidar que cada cual pueda sentirse a gusto y productivo/a en su parte del proceso, y esto no se logra por la tradición patriarcal que intenta seleccionar a los «mejores» (que suelen ser los «arribistas») dejando fuera a muchas otras personas. El arte de cuidar las relaciones debe aprender del «mandar obedeciendo» a lo que cada cual se siente más propenso. Hay quien solo se interesa por la comunicación en los medios, a otras personas se les da bien hablar con la gente en la calle, hay especialistas en tales o cuales cosas diferentes, quien tiene más capacidad para escuchar, y otras para sintetizar; en suma, diferentes inteligencias, incluso algunas que quieren ser las representantes o portavoces. Se trata de cuidar que todo esto funcione internamente con las menores tensiones posibles, y esto es un aprendizaje del cual depende casi siempre el éxito o el fracaso de los procesos.

Enfoque: Estilos «cuidadosos» para distribuirnos las tareas necesarias y construir unos procesos eficientes. Acción: Grupos de trabajo mixtos que elaboran sus propuestas y las van poniendo en marcha, articuladamente. Producto: Buen ambiente de colaboración para que se pueda ir plasmando la idea-fuerza de fondo.

\section{LAS ASTUCIAS Y LOS DESBORDES NECESARIOS}

En el mundo en red actual circulan muchas «posverdades» que solo se sostienen por la circulación rápida e irreflexiva en que nos meten las urgencias de los dirigentes, de los medios. Pero lo que es tangible y vivible de cerca para cada cual y para los sectores cercanos eso sigue siendo un punto de apoyo incuestionable. La mejor forma de superar o evidenciar las medio verdades que nos hacen tragar es con ejemplos positivos de «sí se puede» hacer. Las formas patriarcales quieren mantener el orden y el sistema vigente, o solo cambiarlo para que se siga manteniendo la autoridad heredada, y por lo mismo los desbordes no les gustan, la transducción colectiva va más allá de las jerarquías establecidas. Las astucias de las mujeres en las familias, incluso tradicionales, son una prác- 
tica de una inteligencia no muy valorada pero muy efectiva. Como hacer creer que el patriarca ha tomado la decisión cuando previamente la madre y la familia han consensuado a dónde quiere ir de vacaciones o si es bueno o no hacer tal otra cosa. Los feminismos no son tan solo las luchas en la calle, sino las formas eficientes de desbordar al patriarcado en la vida cotidiana. En ese sentido, revertir es algo más profundo que revolucionar, es mostrar las paradojas internas del poder y en consecuencia hacerle caer en sus propias contradicciones. Ante poderes muy asentados (y que pueden usar la violencia), este tipo de astucias, estrategias reversivas suele ser lo más eficiente.

La gente no es tonta y sabe que no está en el mejor de los mundos, pero el miedo paraliza por la gran fuerza que tienen los poderes globales y los órdenes patriarcales cercanos. Pero sí es posible hacer algo, frente al catastrofismo del «no hay alternativa», o al de «hay que hacer una revolución mundial de todo». Mostramos que sí son posibles algunos «desbordes desde abajo», acciones sociopolíticas transformadoras en la vida cotidiana. Pues ya hay grupos y comunidades («entramados de confianzas y motivaciones») que disfrutan al hacer cosas eficientes (tener resultados con esfuerzos justos) y no aburrirse ni pelearse en el intento, sino más bien sentirnos creativos con las otras personas. Las propias familias ya no son lo que eran, y siguen creciendo las «familias deseadas» por la elección más que por la tradición (no podían evolucionar y eran para toda la vida). Niñas y niños actuales ya viven que hay varias madres y padres, y abuelas y abuelos, que han elegido en cada momento diversos caminos, y que disfrutan de otra manera la vida sin tener que estar sujetos a las normas ancestrales. De igual manera aparecen muchas formas de autoorganización «inteligente» para comprar en colectivo, para asociarse en lo que nos gusta, para el trabajo cooperativo o para las formas del «buen convivir» andino o las «comunidades en transición ecológicas» inglesas o japonesas. Mientras se producen los cambios más globales podemos disfrutar dentro de lo que cabe, y mostrar que es posible no resignarse y revertir y desbordar al orden patriarcal.

Enfoque: Estilos de vida con astucias que revierten y desbordan (y también se dejan desbordar) en los procesos de vida cotidiana. Acción: Monitoreo con (dianas, coherenciómetros) dispositivos para la corrección y mejora de los procesos sobre la marcha. Producto: Resultados visibles a corto plazo, que dan confianza para los programas a medio plazo. Disfrutar con lo que se hace... y que sirva para algo.

\section{LA CAPACIDAD AUTOORGANIZATIVA DE LA GENTE}

Lo patriarcal en la organización suele basarse en las jerarquías familiares o representativas. Los dirigentes quieren ser como «padres» responsables para la comunidad, 
que es lo que precisamente aquí se trata de sobrepasar, con nuevas formas democráticas donde la diversidad de tareas y de las responsabilidades es lo que se prioriza. Es decir, la autoorganización sin patriarcas, basándose en algunas motivaciones colectivas con liderazgos corales. No tanto en los partidos o las empresas, pero sí en algunos movimientos y en movilizaciones concretas esto ya viene funcionando. Diversos colectivos feministas tienen bastantes diferencias ideológicas, pero nos enseñan que en la práctica pueden organizarse para hacer avanzar algunas de sus reivindicaciones (por ejemplo, en la huelga de mujeres del 8 de marzo). La idea-fuerza que une a los feminismos resulta más fuerte que las muchas discrepancias que las separan. De esta forma se pueden ir construyendo experiencias que van más allá de momentos concretos o en algunas zonas del planeta.

Muchos dirigentes se llenan la boca prometiendo democracia participativa, pero a la hora de la verdad solo ponen en marcha alguna ley (u ordenanza) que consagra algún sistema representativo, pues desconocen, o no quieren conocer, otras formas políticas de toma de decisiones que no pasan por elegir unas élites que sustituyan a la gente. Algunos hacen unas asambleas o referéndums, pero se suelen reservar el orden, la información y las preguntas que formulan los dirigentes según su conveniencia. Quien controla la iniciativa y las preguntas iniciales controla todo el proceso, y nos deja en democracias de baja intensidad. Pero hay experiencias de millones de personas (con planes económicos, con presupuestos participativos, con grupos de la sociedad civil que formulan las preguntas, etc.) que abren otras vías para tomar decisiones sin jefes ni élites (su misión será en todo caso ejecutar el mandato que se ha construido colaborativamente, no sustituir a la población).

Se trata de distribuir el poder, al menos en unas cuatro tareas básicas (planificar, legislar, ejecutar y hacer seguimiento), y dentro de cada una de ellas cabe colaborar entre diversas inteligencias (una más técnica, otra más de base, otra más ejecutiva). Son tareas que pueden ser rotativas y funcionar con circuitos de cuidados y poderes no patriarcales, etc. Nuevas formas que experimentamos y que aportamos mediante «talleres deliberativos-operativos». Puede haber alguien que modere, que tome nota, etc., pero una asamblea por grande que sea se puede dividir en grupos más pequeños, y que cada subgrupo parta de una diversidad de opiniones, y que sus portavoces lo muestren a los demás y que la gente pueda ponderar con puntos lo que le parecen las propuestas presentadas. Y sumados los puntos y comparadas las propuestas, se vea cuáles son las que son parecidas y cuáles se pueden articular entre sí, de forma que se puedan construir algunos consensos para la mayoría.

Enfoque: Construcción de experiencias concretas con procesos que lleven a las democracias participativas. Acción: Articulación de grupos de tarea, que ponen en marcha 
de forma coordinada sus propios proyectos y que toman sus decisiones de forma colaborativa. Productos: Ejecución a corto plazo de algunas propuestas, e inicio de otras a medio plazo, que se van siguiendo por grupos interesados en cada tema.

\section{LA «VIDA» FRENTE A LOS VALORES DE ACUMULACIÓN}

La «dictadura de los mercados» y la «especulación global» no solo explotan a buena parte de la humanidad, y se apoyan en el orden patriarcal (sobre el miedo y la seguridad), sino que además están poniendo en peligro las condiciones de la vida en su conjunto. La acumulación de capital ya no se basa solo en la producción capitalista, sino en la especulación con terrenos, las tecnologías, y con el propio dinero. El valor de la vida parece secundario frente al camino «imparable» $\mathrm{y}$ «ciego» por el que nos guían. Muchas feministas han puesto en el centro la defensa de la vida como un valor muy superior al de la acumulación del dinero. Tanto los ecosistemas (las comunidades biológicas) que están en peligro como las comunidades humanas (culturas de la colaboración más básica) están siendo agredidas, porque la economía neoliberal no las contempla más que como «externalidades». Pero resulta que son las bases (no de lucro, pero sí económicas y ecológicas) sobre las que caben ser más felices los humanos. Y desde ahí se diseñan las economías circulares y las economías solidarias que se van propagando en el mundo.

Si las formas de autoorganización de base, del buen convivir y otras, se pueden articular con las democracias participativas reales, y ya hay varias décadas de experiencias en el mundo, entonces se puede plantear dar algunos saltos hacia mayores organizaciones de este tipo, regionales y estatales. En los foros sociales mundiales se plantearon estas alternativas, que poco a poco van siendo tomadas por diversas organizaciones y movimientos sociales. Son formas no patriarcales de hacer, que afectan tanto a las mujeres como a los varones, tanto a los/as adolescentes como a los/as mayores.

Estas propuestas son para pasar a la acción, para encajar con las emociones «sentipensantes» de la gente, no para quedarse en diagnósticos de un patriarca que escribe unas conclusiones. Construir estas ideas-fuerza colaborativas, y empezar a construir los «movimientos de los procomunes», es un horizonte al que se llega por distintos caminos, pero que la realidad del deterioro que sufren las mayorías no deja muchas más posibilidades.

Enfoque: La economía no es más que una parte de la vida; no debe mandar, sino estar subordinada a la vida de los ecosistemas y a la vida de los colectivos humanos. Acción: Construir economías sustentables y solidarias, que se puedan ir coordinando 
con las políticas públicas que les den apoyo. Producto: Planes de acción integrales y sustentables, que partan de poner la vida en el centro de los intereses comunes.

\section{CONCLUSIONES}

Para concluir esta rápida presentación de un proceso solo cabe recordar que no se da nunca tal como está aquí expuesto. Ya son varias décadas tratando de hacer este tipo de propuestas, e incluso con buenos resultados y con algunos fracasos, para saber que las condiciones concretas de cada lugar o de cada proceso sectorial son muy diferentes y determinan qué se puede hacer y qué no. Por eso cabe insistir en que lo más importante, de la capacidad de adecuación, es partir de un «grupo motor» mixto y cuidador para ir monitoreando-evaluando cada salto del proceso. Estos elementos que presentamos se pueden entender como «preguntas» que nos debemos hacer más que como algo rígido que cumplir. El estilo que llamamos «transductivo» es tanto una provocación para la acción colectiva como un estímulo para ir rectificando en cada salto. Y para evaluar si lo estamos haciendo bien, un buen índice es: a) cuánto nos dejamos desbordar, cuánto estamos aprendiendo de la propia práctica; $b$ ) si en el grupo motor sigue habiendo buen ambiente y sus miembros se sienten útiles; y c) si la gente nota que se van produciendo algunos resultados en el camino de la transición hacia una mejor calidad de vida y un mejor convivir.

\section{BIBLIOGRAFÍA}

Beauvoir, S. (1999). El segundo sexo. Madrid. Cátedra.

Braidotti, R. (2006). Transposiciones. Sobre la ética nómada. Barcelona. Gedisa.

Bourdieu, P. (2000). La dominación masculina. Barcelona. Anagrama.

Butler, J. (2001). El género en disputa. México. Paidós.

Carrasco, C. (2001). «La sostenibilidad de la vida humana ¿un asunto de mujeres?». Mientrastanto, 82

Curbelo, A. y Hernández, L. (2017). Otro trabajo social es posible. Disponible en www. RedCIMAS.org

Dalla Costa, M. R. (1975). Las mujeres y la subversión de la comunidad. Madrid. Siglo XXI.

Davis, A. (1981). Mujeres, raza y clase. Madrid. Akal. 
Dominelli, L. y MacLeod, E. (1999). Trabajo Social Feminsita. Madrid. Cátedra feminismos.

Duran, M. Á. (2010). Tiempo de vida y tiempo de trabajo. Bilbao. Fundación BBVA.

Engels, F. (1977). El origen de la familia, la propiedad privada y el Estado. Madrid. Fundamentos.

Federicci, S. (2011). Caliban y la bruja. Mujeres, cuerpo y acumulación originaria. Buenos Aires. Tinta Limón.

Galceran, M. (2009). Deseo (y) libertad. Una investigación sobre los presupuestos de la acción colectiva. Madrid. Traficantes de Sueños.

Guattari, F. (2004). Plan sobre el planeta. Capitalismo mundial integrado y revoluciones moleculares. Madrid. Traficantes de Sueños.

Gutiérrez Aguilar, R. (2017). Horizontes comunitario-populares. Producción de lo común más allá de las políticas estado-centricas. Madrid. Traficantes de Sueños.

Haraway, D. (1995). Ciencia, cyborgs y mujeres: la reinvención de la naturaleza. Madrid. Cátedra.

Henderson, H. (1985). «Post-econimic policies for post-industrial societies». Revision, 72.

Hernando, A. (2019). La fantasía de la individualidad. Sobre la construcción sociohistórica del sujeto. Madrid. Traficantes de Sueños.

Herrero, Y. (2012). Vivir bien con menos. Ajustarse a los límites fisicos con criterios de justicia. (Disponible en internet).

Izquierdo, M. J. (1998). El malestar en la desigualdad. Barcelona. Cátedra.

Juliano, D. (1992). El juego de las astucias. Mujer y construcción de modelos sociales alternativos. Madrid. Horas y Horas.

Keller, E. F. (1991). Reflexiones sobre género y ciencia. Valencia Inst. Alfonso el Magnifico.

Knorr-Cetina, K. D. (2005). La fabricación del conocimiento: un ensayo sobre el carácter constructivista y contextual de la ciencia. Bernal. Universidad Nacional de Quilmes.

Kristeva, J. (1991). Extranjeros para nosotros mismos. Barcelona. Plaza \& Janés.

- (1995). Las nuevas enfermedades del alma. Madrid. Cátedra

Laval, P. y Dardot, P. (2015). Común. Ensayo sobre la revolución en el siglo XXI. Barcelona. Gedisa.

Maturana, H. y Verden Zöller, G. (1993). Amor Y Juego. Santiago de Chile: Editorial Instituto de Terapia Cognitiva.

Ostrom, E. (1990). Governing the commons. Cambridge University Press. 
Pérez Orozco, A. (2014). Subversión feminista de la economía. Aportes para un debate sobre el conflicto capital-vida. Madrid. Traficantes de Sueños.

Mies, M. y Shiva, V. (1993). Ecofeminismo. Teoría, crítica y perspectivas. Icaria: Antrazyt.

Palop, M. E. R. (2019). Revolución feminista y políticas de lo común frente a la extrema derecha. Barcelona. Icaria

Red CIMAS (2015). Metodologías participativas. Sociopraxis para la creatividad social. Madrid. Dextra.

Rivera, S. (1987). «El potencial epistemológico y teórico de la historia oral: de la logica instrumental a la descolonización de la historia». Bolivia. Revista Temas Sociales.

Rolnik, S. (1986). Micropolitica. Cartografias del deseo. Madrid. Traficantes de Sueños.

Sabadell, J. (2011). Desbordamientos. Transformaciones culturales y políticas de las mujeres. Barcelona. Icaria.

Sassen, S. (2003). Contrageografias de la globalización. Madrid Traficantes de Sueños.

Spivak, G. (2001). Critica de la razón poscolonial. Hacia una crítica del presente evanescente. Madrid. Akal.

Tiriba, L. (2003). Economia popular en Catanni, Outra Economia. Porto Alegre. Veraz.

Vega, C. (2009). Culturas del cuidado en transición: espacios, sujetos e imaginarios en una sociedad de migración. Barcelona UOC.

Villasante, T. R. (2014). Redes de vida desbordantes. Fundamentos para el cambio desde la vida cotidiana. Madrid. La Catarata.

- (2017). Democracias trasformadoras. Experiencias emergentes y alternativas desde los comunes. Barcelona. El Viejo Topo. 